
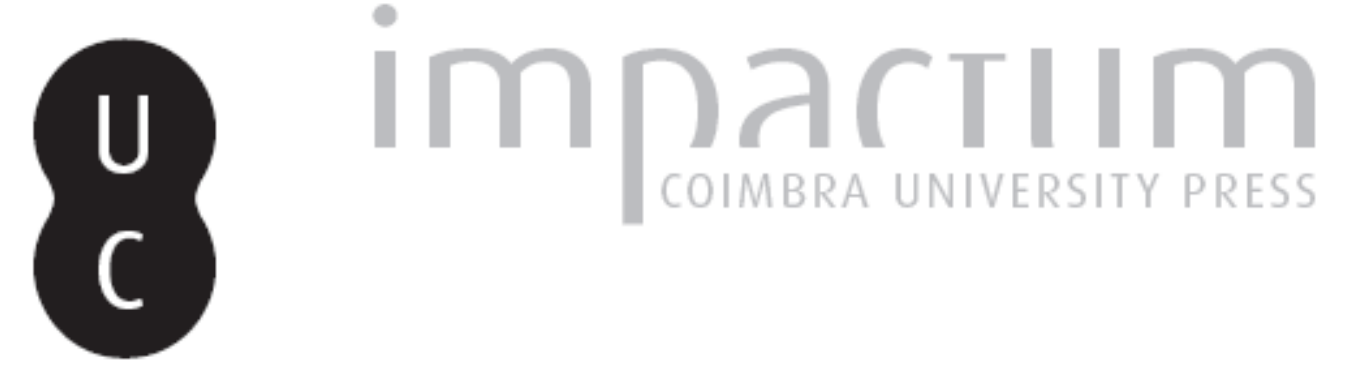

\title{
Educação para prevenção de desastres: a persistência do conhecimento tecnocientífico e da individualização do risco
}

Autor(es): Sulaiman, Samia Nascimento

Publicado por: Imprensa da Universidade de Coimbra

URL persistente:

URI:http://hdl.handle.net/10316.2/44188

DOI:

DOI:https://doi.org/10.14195/1647-7723_25-2_2

Accessed : $\quad$ 26-Apr-2023 10:22:09

A navegação consulta e descarregamento dos títulos inseridos nas Bibliotecas Digitais UC Digitalis, UC Pombalina e UC Impactum, pressupõem a aceitação plena e sem reservas dos Termos e Condições de Uso destas Bibliotecas Digitais, disponíveis em https://digitalis.uc.pt/pt-pt/termos.

Conforme exposto nos referidos Termos e Condições de Uso, o descarregamento de títulos de acesso restrito requer uma licença válida de autorização devendo o utilizador aceder ao(s) documento(s) a partir de um endereço de IP da instituição detentora da supramencionada licença.

Ao utilizador é apenas permitido o descarregamento para uso pessoal, pelo que o emprego do(s) título(s) descarregado(s) para outro fim, designadamente comercial, carece de autorização do respetivo autor ou editor da obra.

Na medida em que todas as obras da UC Digitalis se encontram protegidas pelo Código do Direito de Autor e Direitos Conexos e demais legislação aplicável, toda a cópia, parcial ou total, deste documento, nos casos em que é legalmente admitida, deverá conter ou fazer-se acompanhar por este aviso.

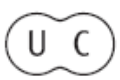




\section{EDUCAÇÃO PARA PREVENÇÃO DE DESASTRES: A PERSISTÊNCIA DO CONHECIMENTO TECNOCIENTÍFICO E DA INDIVIDUALIZAÇÃO DO RISCO*}

EDUCATION FOR DISASTER PREVENTION: THE PERSISTENCE OF SCIENTIFIC-TECHNICAL KNOWLEDGE AND THE INDIVIDUALIZATION OF RISK

Samia Nascimento Sulaiman

Instituto de Energia e Ambiente, Universidade de São Paulo (Brasil) ORCID 0000-0002-2789-2286 samia.sulaiman@gmail.com

\section{RESUMO}

A recente Política Nacional de Proteção e Defesa Civil Brasileira (Lei n’ 12.608/2012) ressaltou a cultura de prevenção e sua inserção no currículo escolar nacional. Este artigo apresenta os resultados da pesquisa, exploratória e qualitativa, sobre o estado da arte de conteúdos e abordagens educativas para a prevenção de desastre no Brasil. Os dados foram obtidos por pesquisa bibliográfica, documental e observação participante, a partir de 3 recortes: temático (inundações/ enchentes e deslizamentos), temporal (de 2011 a 2014) e geográfico (região metropolitana do ABC Paulista). 0 corpus foi composto por materiais impressos/digitais e atividades de informação/capacitação. Por meio do método da análise de conteúdo, identificamos dois conteúdos (conhecimentos tecnocientíficos e comportamentos/atitudes de prevenção e auto-proteção) e duas abordagens educativas (transmissão-assimilação e individualização do risco), que perpetuam uma "inquestionabilidade do risco", alheia às causas profundas do risco, o que fragiliza as ações de redução de risco baseada na comunidade.

Palavras-chave: Educação, prevenção, risco, desastre, causas profundas.

\section{ABSTRACT}

The recent National Policy on Protection and Civil Defense of Brazil (Law no 12.608/2012) highlighted the culture of prevention and its insertion in the national school curriculum. This article presents the results of the exploratory and qualitative research about the state of the art of the content and educational approaches to disaster prevention in Brazil. The data were obtained through literature, documentary and participant observation research, from three examples: thematic (floods and landslides); temporal (from 2011 to 2014); and geographic (metropolitan region of ABC Paulista). The corpus consisted of printed/digital materials and information/training activities. Through the content analysis method, we identified two contents (scientific-technical knowledge and behaviors/attitudes for prevention and self-protection) and two educational approaches (data transmission-assimilation and individualization of risk), which perpetuate an "unquestionability of risk", unrelated to the root causes of risk, and this weakens communitybased risk reduction actions.

Keywords: Education, prevention, risk, disaster, root causes.

\footnotetext{
* O texto deste artigo corresponde a uma comunicação apresentada no IV Congresso Internacional de Riscos, tendo sido submetido em 16-05-2017, sujeito a revisão por pares a 22-09-2017 e aceite para publicação em 22-11-2017. Este artigo é parte integrante da Revista Territorium, $n .{ }^{\circ} 25$ (II), 2018, ${ }^{\circ}$ RIscos, ISSN: 0872-8941.
} 


\section{Introdução}

Fomentar a resiliência na sociedade contemporânea está no caminho para a redução da ocorrência de desastres, e as estratégias para tal intento têm sido revistas ao longo das últimas três décadas. A última Conferência Mundial das Nações Unidas, realizada no Japão em 2015, sinalizou que uma gestão eficiente e eficaz na redução da probabilidade de ocorrência de desastres necessita da participação dos atores pertinentes dentro de um processo de governança. 0 resultado da conferência foi compilado no Marco de Sendai para a Redução de Risco de Desastre 2015-2030 que retoma as diretrizes do Marco de Ação de Hyogo 2005-2015: aumento da resiliência das nações e das comunidades que, por sua vez, sistematizou as questões levantadas no Marco Internacional de Ação do Decênio Internacional para a Redução dos Desastres Naturais de 1989 e na Estratégia de Yokohama para um Mundo Mais Seguro de 1994.

Nesse caminhar, as experiências internacionais em contextos de eventos extremos foram ampliando o entendimento sobre as causas dos desastres naturais e as medidas de mitigação e adaptação adequadas a esse cenário. É possível notar, então, a ampliação da gestão focada no desenvolvimento de medidas técnico-científicas, para estudos e intervenções que consideram a vulnerabilidade das populações e seus fatores sociais, de modo a apoiar a construção de uma cultura de prevenção e de resiliência até a governança e participação política da sociedade.

Esse entendimento foi incorporado à legislação brasileira, especificamente com a promulgação da Política Nacional de Proteção e Defesa Civil Brasileira (Lei $n^{\circ}$ 12.608) em 2012. A nova Política foi uma resposta governamental aos vultosos e seguidos desastres naturais ocorridos em diversas regiões do país: inundações em Santa Catarina (2008), em Alagoas e Pernambuco (2010) e na região serrana do Rio de Janeiro (2011), que também sofreu com deslizamentos, que evidenciaram a debilidade do país frente a eventos naturais extremos (BM, 2012a,b,c,d).

A Lei $\mathrm{n}^{\circ}$ 12.608/2012 ressaltou a abordagem mutissetorial do risco de desastre para a promoção do desenvolvimento sustentável, dando prioridade às ações preventivas relacionadas à minimização de desastres e enfocando a participação social. Nesse sentido, alterou a Lei de Diretrizes e Bases da Educação Nacional e incluiu na educação básica conteúdos de proteção e defesa civil (BRASIL, 2012). Diante desse cenário internacional e nacional, este trabalho buscou identificar conteúdos e processos educativos relacionados à educação para prevenção e avaliar se respondem às demandas contemporâneas de fomento à resiliência.

Para tanto, esta pesquisa orientou-se pelas seguintes perguntas de investigação: 0 que é educar para a prevenção de desastres naturais? Quais são seus limites e possibilidades?, sendo, portanto, de caráter exploratório, para explicitar um problema de modo a permitir maior entendimento sobre ele (A. Gil, 1994), e qualitativo relacionando concepções teóricas da abordagem, a realidade empírica e os pensamentos sobre a realidade (M. Minayo, 2010). Partiu-se da hipótese de que a educação para a prevenção de desastres naturais é informativa e comportamentalista para disseminar conhecimentos e indicar atitudes para a adaptação das populações e, assim, não problematiza a construção social do risco e não estabelece diálogo crítico com a sociedade.

Para comprovar essa afirmação, a pesquisa buscou identificar, na literatura brasileira e internacional: a) as abordagens teórico-metodológicas que baseiam o conceito e a gestão dos desastres, e sua repercussão nas ações educativas; b) os referenciais legais e institucionais dessa gestão no Brasil e sua extensão na produção de materiais e organização de atividades de informação/ capacitação no país; e c) a caracterização das áreas de risco de inundação e deslizamento nas cidades brasileiras e as informações/ações educativas nesse contexto.

Os resultados desse levantamento permitiram identificar o estado da arte de conteúdos e práticas educativas para a prevenção de desastres no Brasil, tendo como recorte temático as inundações/enchentes e deslizamentos; como recorte temporal o período compreendido entre março de 2011 e março de 2014; e como recorte geográfico, a região metropolitana do $A B C$ paulista, no Estado de São Paulo, sudeste do Brasil (fig. 1).

A região do $A B C$, composta por 7 municípios (Santo André, São Bernardo do Campo, São Caetano do Sul, Diadema, Mauá, Ribeirão Pires e Rio Grande da Serra), perfaz uma área de $825 \mathrm{~km}^{2}$ e reúne mais de 2,5 milhões de habitantes (IBGE, 2017), situando-se na área metropolitana de São Paulo. Foi o primeiro centro da indústria automobilística brasileira, o que impulsionou a urbanização e o adensamento populacional acelerado e desordenado, vinculados a atividades secundárias e terciárias. Tem $56 \%$ de sua superfície ocupada por mananciais (R. Rolnik, 1999), o que problematiza a ocupação sem controle e com assentamentos precários que, além da precariedade socioeconômica e habitacional, evidencia alta densidade de ocupação, irregularidade fundiária, distância de locais de oferta de emprego e vulnerabilidade a impactos, como inundações/enchentes, resultantes da ocupação desordenada no entorno da represa Billings. Esses assentamentos ainda representam um problema ambiental - pela ameaça à qualidade da água de um dos maiores reservatórios da Região Metropolitana de São Paulo -, já que revelam fragilidades na rede de saneamento (Y. Veyret, e N. Richemond, 2007; M. Alheiros, 2011; L. Cerri e F. Nogueira, 2012). 
No reverso desse cenário, a região tem experienciado ações de gestão de risco que se destacam do restante do país, especialmente pelo apoio do Consórcio Intermunicipal do $A B C$ e sua interlocução com instituições de pesquisa. O Consórcio firmou contrato com o Instituto de Pesquisas Tecnológicas de São Paulo, em 05/11/2011, para mapeamento de áreas de risco e respetiva concepção de intervenções estruturais. Teve como objetivo a elaboração dos Planos Municipais de Redução de Riscos em Rio Grande da Serra, Ribeirão Pires e Santo André, para, em associação com os planos das outras 4 cidades da região, articular um Programa Regional de Redução de Riscos a Desastres Naturais (IPT, 2014). Mais recentemente, em 2015, junto com a Universidade Federal do $A B C$, o Consórcio promoveu o Programa de Extensão “Apoio à Construção de Política Pública Regional de Gestão de Risco de Desastres no Grande ABC" com oficinas direcionadas a capacitar técnicos e gestores municipais, agentes de defesa civil, consultorias e organizações não governamentais para elaboração, aprimoramento e implementação da gestão do risco e contribuir para a interação e troca de experiência entre os diversos municípios da Região do Grande $A B C$, bem como de órgãos de governo da esfera municipal, estadual e federal, envolvidos com a gestão do risco (UFABC, 2015).

Diante do campo que se abre à educação para prevenção de desastres naturais, segundo as novas diretrizes brasileiras da Política Nacional de Proteção e Defesa
Civil (de 2012), este trabalho pretendeu colaborar com a reflexão sobre os limites e as possibilidades do tema de desastres para a conscientização e mobilização social em prol de uma condição de vida com mais qualidade, justiça e segurança e o papel da educação nesse processo.

\section{Metodologia}

O trabalho apresenta características multimetodológicas, designadamente pesquisa bibliográfica, pesquisa documental e observação participante, e envolveu fontes de linguagem verbal (oral e escrita) e linguagem não-verbal (signos visuais) tanto de informação pública (por meio de folhetos, cartilhas, cartaz, vídeo), quanto de treinamento/capacitação em cursos e reuniões comunitárias, sendo analisados como elementos que compõem o contexto atual de educação para prevenção de desastres naturais no Brasil.

Para a análise dos dados foi utilizada a análise de conteúdo, permitindo, a partir da definição de indicadores (quantitativos ou qualitativos) interpretados a partir dos textos expressos nas fontes, a identificação de conteúdos latentes relativos às condições de produção (ou, eventualmente, de recepção) das mensagens (L. Bardin, 2009[1977]). Seguindo três etapas (a descrição, a inferência e a interpretação), a análise de conteúdo articula a observação/descrição das características do texto e a dedução lógica dos fatores que as determinam,
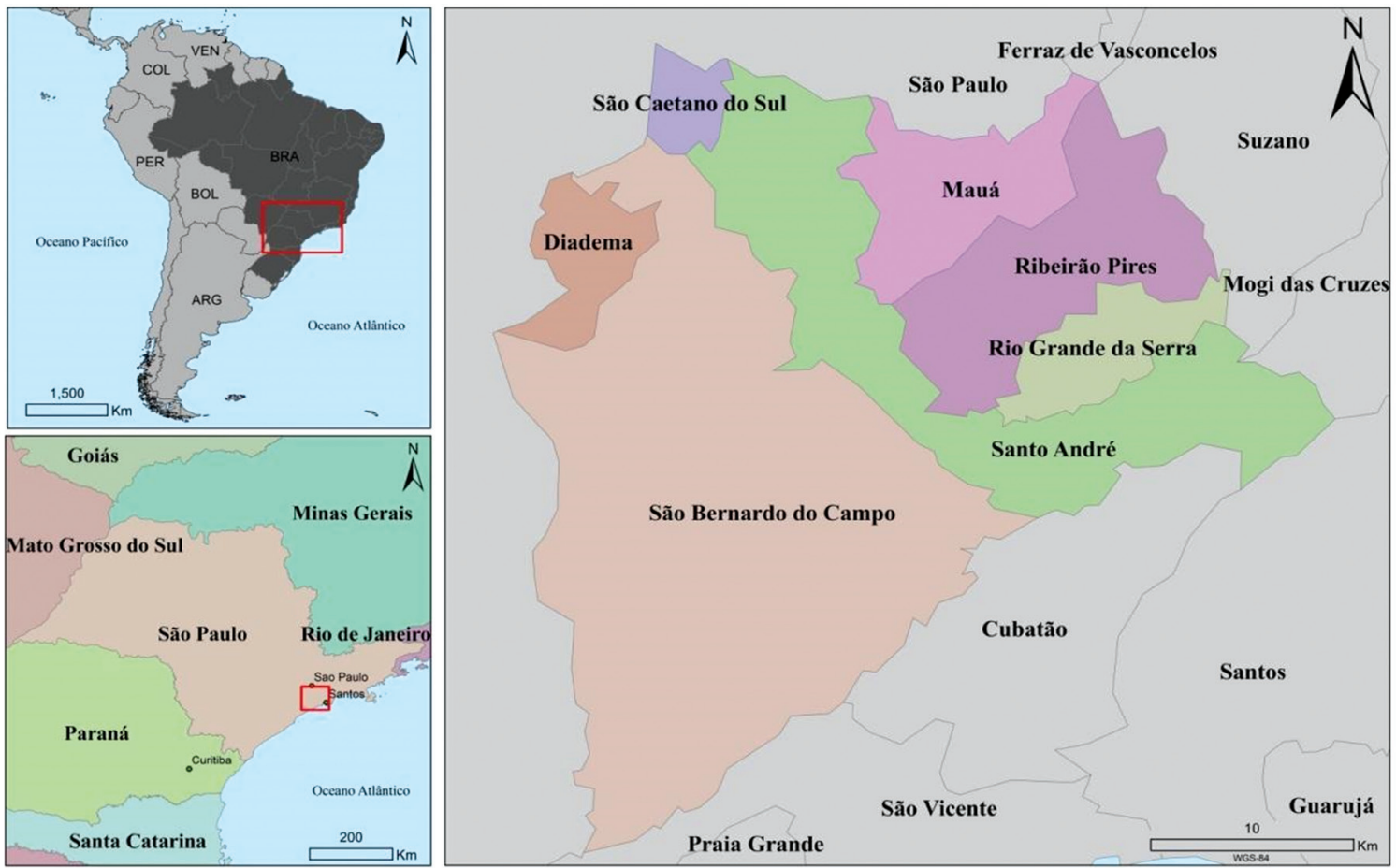

Fig. 1 - Localização da região do $A B C$ Paulista.

Fig. 1 - Location of the $A B C$ Paulista region. 
estabelecendo "uma correspondência entre as estruturas semânticas ou linguísticas e as estruturas psicológicas ou sociológicas (por exemplo: condutas, ideologias $e$ atitudes) dos enunciados" (Ibid., p. 43).

Antes da análise do corpus, realizou-se uma categorização apriorística da abordagem para gestão de riscos de desastres com base no modelo desenvolvido pela Agência de Coordenação das Nações Unidas para o Socorro em Desastres (UNDRO, em inglês). 0 modelo baseia-se em 4 ações estratégicas: identificação/ análise de riscos; medidas de prevenção; planejamento para situações de emergência; e informação pública e treinamento (UNDRO, 1991). Como a $4^{\mathrm{a}}$ ação desse modelo se articula com os objetos de análise desta pesquisa, foram utilizadas as três primeiras ações estratégicas da UNDRO como categor ias apriorísticas de análise do corpus. Através da sua leitura e exploração, realizou-se a categorização não apriorística que deu origem às 10 subcategorias temáticas de análise. A relação entre o modelo da UNDRO, as categorias e as subcategorias, com os respectivos conteúdos relacionados, está descrita no QUADRo I.

A primeira categoria "identificação/análise de riscos" reuniu as mensagens que apontaram informações sobre os processos relacionados com a ocorrência de inundações/enchentes e deslizamentos. A subcategoria “condicionantes naturais" agrupou mensagens sobre fenômenos naturais, características geoambientais e processos climáticos relativos a esses riscos, como se exemplifica no trecho a seguir: "principal fator que provoca o risco: chuvas intensas e concentradas" (folheto Prevenção em áreas de risco, Diadema, 2013).
A subcategoria "condicionantes antrópicas" agrupou mensagens sobre ações humanas relacionadas com os riscos em causa, como "O lixo jogado nas ruas, nos terrenos baldios, nas margens dos córregos e rios é um dos grandes vilões que contribuem para a ocorrência de cheias" (folheto Boca de lobo não come lixo,São Caetano do Sul, s/d). Em "sinais de perigo", foram identificadas as mensagens direcionadas a apontar elementos, características, processos relativos à instalação desses riscos, como "Verifique os sinais de risco: trincas e rachaduras; aparecimento de degraus ou de rebaixamento no terreno [...]" (folheto Operação Guarda-Chuva 2014 ,SBC, 2013).

A segunda categoria, definida como "medidas de prevenção", envolveu as mensagens que indicavam ações para a convivência com o risco, por meio da orientação de ações e comportamentos adequados referentes a “moradia”, “água”, “resíduos sólidos”, “vegetação” e "gerenciamento". Por exemplo, a frase "Plante Grama ou capim nas encostas do terreno [...]" (folheto Prevenção em áreas de risco - Mauá, Mauá, s/d.) foi classificada na subcategoria “vegetação". Já a sentença "O que é o PMRR? É um plano que contém medidas de prevenção e correção para reduzir os riscos de escorregamento [...]" (folheto Prevenção em áreas de risco, Diadema, 2013), foi integrada na subcategoria "gerenciamento". Notese que as cinco subcategorias geralmente aparecem em conjunto, tal como se verifica no folheto Juntos, vamos proteger Santo André das chuvas:

\section{"Mas é dever de cada um colaborar para diminuir consequências mais graves em dias de chuva. Veja como é simples seguir algumas dicas:}

QUADRO I - Categorização dos conteúdos e abordagens de educação para prevenção de desastres.

TABLE I - Categorization of the content and education approaches of for disaster prevention.

\begin{tabular}{|c|c|c|}
\hline $\begin{array}{l}\text { Categorias apriorísticas de análise } \\
\text { (UNDRO, 1991) }\end{array}$ & $\begin{array}{l}\text { Subcategorias não } \\
\text { apriorísticas de análise }\end{array}$ & Conteúdos relacionados \\
\hline \multirow{3}{*}{ identificação/análise de riscos } & Condicionantes naturais & Processo físico de inundações/enchentes e deslizamentos \\
\hline & Condicionantes antrópicas & Uso e ocupação do solo \\
\hline & Sinais de perigo & Evidências no terreno/na edificação de instalação do risco \\
\hline \multirow{5}{*}{ medidas de prevenção } & Moradia & Localização da moradia \\
\hline & Água & Drenagem pluvial e rede de esgoto \\
\hline & Resíduos sólidos & Destinação de lixo/entulho \\
\hline & Vegetação & Presença/ausência e tipo de vegetação \\
\hline & Gerenciamento & Ações de prevenção e resposta \\
\hline \multirow{2}{*}{$\begin{array}{l}\text { planejamento para situações de } \\
\text { emergência }\end{array}$} & Responsáveis & Atores e/ou instituições envolvidas \\
\hline & Medidas de segurança & $\begin{array}{l}\text { Ações/comportamentos de auto-proteção (antes, durante e } \\
\text { depois) }\end{array}$ \\
\hline Informação pública e treinamento & \multicolumn{2}{|c|}{ Materiais e atividades sob análise nesta pesquisa } \\
\hline
\end{tabular}


- Nunca jogue lixo nas ruas, córregos ou rios;

- Mantenha sempre quintais e bueiros limpos para a água da chuva escoar com rapidez;

- Mantenha ralos e calhas desobstruídos;

- Nunca bloqueie a passagem das águas que vêm das casas acima da sua;

- Embale bem o lixo e coloque-o em locais altos como caçambas e lixeiras;" (Santo André, s/d.).

A terceira categoria, "planejamento para situações de emergência”, incluiu as mensagens de orientação em caso da iminência/ocorrência de um desastre, bem como as entidades responsáveis por esse planejamento. A subcategoria "responsáveis" envolveu mensagens que abordaram a Defesa Civil e seu papel em situações de emergência, como se observa na cartilha Defesa civil para crianças: caderno para colorir:

"Para que serve a Defesa Civil? A Defesa Civil é um órgão do Governo Federal, Estadual ou do Município que trabalha antes, durante e depois de um desastre. Trabalha antes, ensinando as pessoas tudo o que devem fazer para evitar desastres [...]. Isso é a chamada fase de Prevenção. Trabalha durante, auxiliando outros órgãos como Bombeiros, a Polícia, etc. [...]. Chamamos essa de Fase de Socorro. Trabalha após um desastre, quando cuida das pessoas que perderam suas casas [...]. Essa é a Fase de Assistência. Quando o desastre acaba, o trabalho da Defesa Civil ainda continua, até que consiga deixar as pessoas tranquilas e os locais atingidos em ordem novamente [...]. É um trabalho mais demorado, mas muito importante, e essa fase é chamada de Fase de Reconstrução" (SBC, s/d: 3-4).

Mensagens que indicam ações e comportamentos de auto-proteção antes, durante e após a ocorrência de uma inundação/enchente e deslizamento, foram classificadas como "medidas de segurança". No vídeo Áreas de risco: informação para prevenção, que aborda especificamente as áreas de risco de deslizamentos, afirma-se que " $a$ população das áreas de risco, ela [sic] também pode exercer o que a gente chama de auto-proteção, ou seja, ela pode observar esses sinais de que pode acontecer um deslizamento e tomar providência de chamar a Defesa civil e sair da sua casa" (Mauá e IPT, 2012). O vídeo, de 11 minutos e 28 segundos, foi produzido com recursos federais e realizado pelo IPT para a Prefeitura de Mauá no âmbito do Plano Municipal de Redução de Riscos. Segundo o coordenador da produção, "a ideia é que o vídeo seja difundido para todos, podendo ser usado em aulas ou qualquer outra situação pertinente. Ele é um instrumento de educação para alunos, técnicos que trabalham na área e principalmente para os moradores" (IPT, 2012a).
A quarta categoria "informação pública e treinamento" refere-se aos materiais e às práticas indicadas para que se construa uma cultura de enfrentamento do risco junto a equipes locais e à população. Ela não faz parte das categorias de análise das fontes deste trabalho porque se está analisando exatamente os conteúdos e as abordagens educativas presentes nessa ação estratégica proposta pela UNDRO. É a partir dela que se desenvolvem todas as outras ações estratégicas (identificação/análise de riscos, medidas de prevenção e planejamento para situações de emergência), que, neste trabalho, foram utilizadas como categorias de análise de conteúdo dos materiais e das práticas de informação pública e treinamento dentro do campo da educação para prevenção de desastres.

Além da pesquisa documental dos materiais impressos e audiovisuais de disseminação, no período da pesquisa foi possível obter dados a partir de observação participante em duas atividades distintas. Primeiro, em duas realizações do curso de capacitação “Mapeamento de Área de Risco de Escorregamento e Solapamento de Margens de Córregos", ministrado pelo IPT, nos municípios de Rio Grande da Serra e Ribeirão Pires. 0 curso, dentro do convênio do Consórcio do ABC com o IPT, teve como objetivo instrumentalizar os participantes, especialmente os agentes de defesa civil - e em menor número gestores públicos, funcionários da prefeitura, moradores em área de risco, voluntários - sobre como identificar e avaliar uma área de risco, por meio de aula expositiva, trabalho de campo e produção de mapas de risco. Segundo, em reuniões comunitárias realizadas pela Defesa Civil e a Secretaria de Habitação de São Bernardo do Campo dentro da Operação Guarda-Chuva (OGC), nas edições 2012-2013 e 2013-2014. Como se lê nos folhetos informativos da OGC, o seu objetivo foi "Informar para Prevenir: Todas as áreas em situações de risco receberam materiais informativos e, nas 38 áreas prioritárias, foram realizadas reuniões de reforço de informação" (SBC, 2012a, 2013).

Após a categorização e subcategorização temáticas das mensagens do corpus (fig, 2), passou-se à etapa interpretativa do conteúdo manifesto relativo às características de um cenário de desastre de inundação/ enchente/ deslizamento e às ações adequadas para evitá-lo ou enfrentá-lo, com o intuito de aumentar a consciência das pessoas sobre o risco e a sua capacidade de enfrentamento. Primeiramente, foram obtidos dois conteúdos educativos:

1) conhecimentos tecnocientíficos e

2) comportamentos e atitudes de prevenção e autoproteção.

Em seguida, foram observadas duas abordagens educativas:

1) transmissão-assimilação e

2) individualização do risco. 
Conhecer para prevenir: a educação como transmissão do conhecimento científico

A abordagem educacional sobre os riscos de desastres iniciou-se principalmente nas disciplinas de ciências e geografia, apresentando fenômenos mundiais, sem

a conexão com o local e sem as medidas práticas disponíveis de proteção face à sua ocorrência. Segundo M. Petal (2008), frente a essa lacuna, caberia o engajamento das crianças na avaliação local dos riscos e vulnerabilidade e no levantamento de recursos e capacidades para minimizar a vulnerabilidade e o risco, colocando a preparação para a resposta em último lugar, para apenas compensar as deficiências em prevenção.

Essa limitação também foi observada pela UNESCO e UNICEF que realizaram um mapeamento em 30 países sobre a integração da redução de risco de desastres nos currículos escolares. Os resultados do estudo apontaram uma "infusão limitada”, relacionada com: a) a restrição da temática a determinados assuntos, normalmente de ciências físicas (Geografia e Ciências), cujo conteúdo já abarca o estudo dos riscos naturais; b) a aprendizagem para a aquisição de conhecimentos e habilidades práticas que não responde ao envolvimento da comunidade e às propostas internacionais de mitigação e resiliência; c) a abordagem de prevenção e resposta ao desastre que impede as ações de mitigação de desastres relacionadas à comunidade e às metas de resiliência (UNESCO, UNICEF, 2012, p. 17).

Segundo a publicação, o que se faz em matéria de educação para a redução de risco de desastre é explorar a ciência básica de riscos ambientais e apontar medidas de segurança. Essa abordagem, por um lado, inviabiliza uma cobertura sistemática do perigo e, por outro, inverte a escala de importância das ações da prevenção e mitigação para as medidas de preparação. O documento ainda explicita que "entender a ciência de um perigo por si só não desenvolve a propensão para a pró-ação, focando-se exclusivamente na segurança sem examinar a prevenção e a mitigação implica na inevitabilidade do que está para acontecer. A atenção é, portanto, desviada das dimensões sociais, econômicas e políticas dos desastres, e do tratamento das vulnerabilidades e da construção da resiliência" (UNESCO, UNICEF, 2012, p. 20).

No campo da educação para prevenção de desastres naturais, observa-se que os conteúdos educativos são desenhados em torno dos conhecimentos técnicocientíficos como estratégia de fornecer informações que, neste trabalho, fizeram parte da primeira categoria de análise de conteúdo do corpus: "identificação/ análise de riscos". E das 3 subcategorias a ela associadas ("condicionantes naturais", "condicionantes antrópicas" e "sinais de perigo"), a que sobressaiu foi "sinais de perigo", com mensagens direcionadas a apontar elementos, características, processos relativos à instalação dos riscos de inundação/enchente e deslizamento. Conjugando texto e imagem, as mensagens sobre sinais de perigo buscaram estimular a percepção de risco das pessoas, para que elas sigam as recomendações de prevenção e auto-proteção (fig. 2).

A informação sobre os sinais de perigo de ocorrência de uma inundação/enchente e deslizamento apoia-se em causas físicas e humanas, constituindo conteúdos baseados na premissa de "conhecer para prevenir". Premissa que se fundamenta no 'conhecer' como aquisição de conhecimento tecnocientífico, de forma passiva, acrítica e utilitarista, para a adoção, pelos envolvidos com áreas suscetíveis, de comportamentos de convivência com o risco e preparação para o desastre.

A perspectiva da educação para prevenção de desastre que se baseia na premissa "conhecer para prevenir", acaba difundindo o paradigma hegemônico da ciência e da tecnologia e perde-se a oportunidade de reconhecer saberes e produzir conhecimentos novos e contextualizados que mobilizem os envolvidos para uma gestão compartilhada frente aos riscos de desastre. Há a transmissão de informações de base tecnocientífica, para desenvolver a percepção do risco presente/existente, chamando a atenção sobre a constituição do risco instalado, como se enuncia e se visualiza no vídeo Áreas de risco: informação para a prevenção:

"Elas [as pessoas] chegam a esse local, uma área de encosta por exemplo. Os primeiros ocupam a parte de baixo que é mais fácil de se ocupar, daí os últimos vão ocupar as partes mais inclinadas da encosta [...] quando você vai ter uma ocupação, a população faz uma escavação no talude natural formando, então, o talude de corte, esse material escavado é lançado na encosta formando o aterro lançado" (IPT, 2012a).

A difusão dos conhecimentos é importante mas a sua simples transmissão para assimilação do público não significa mudança. No caso dos deslizamentos em área de encosta, por exemplo, afirma-se que a "cultura popular de "morar no plano"” (MC et al., s/d.:19) e o padrão de intervenção no terreno por "corte e aterro" do talude natural (Cerri, Nogueira, 2012, p. 288), tornam a área mais suscetível à movimentação. No entanto, o conhecimento sobre a ação inadequada de ocupação de uma encosta não depende do conhecimento do termo técnico "talude", partindo-se da premissa de que os conhecimentos locais devem ser "melhorados" com a informação técnica, para a formação de "um olhar mais técnico" (Silva, Macedo, 2007).

A informação sobre como identificar o perigo toma como pressuposto que o risco é inevitável, cabendo, ao público, apenas assimilar elementos que permitam identificá-lo e, assim, adotar medidas de segurança 


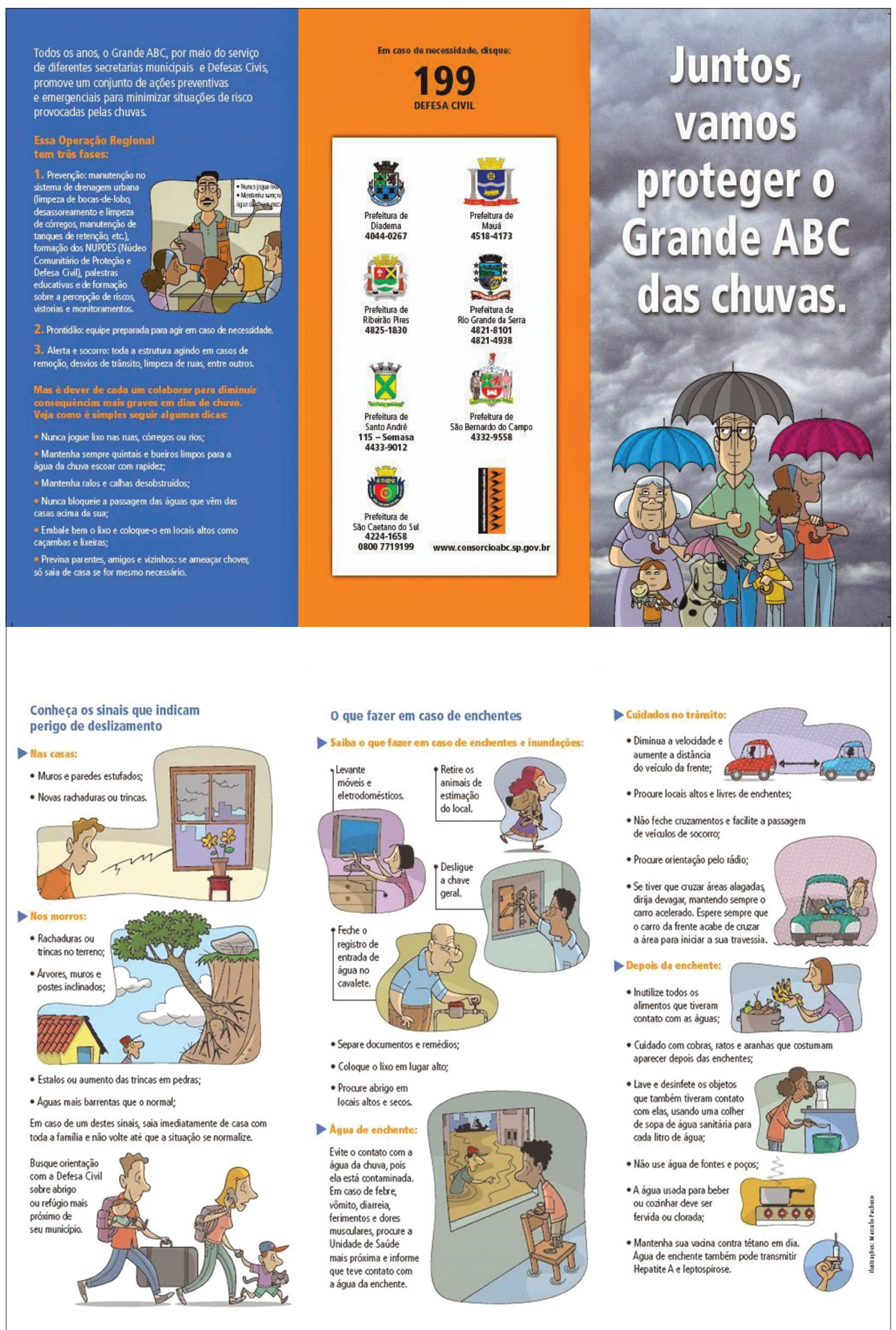

Fig. 2 - Frente e verso de folheto educativo sobre prevenção de inundações/enchentes e deslizamentos (Fonte: Consórcio (s/d.)).

Fig. 2 - DFront and back of educational leaflet on flood and landslide prevention (Source: Consórsio (s/d.)). 
em um contexto materializado de risco. Os conteúdos educativos de base tecnocêntrica deixam de abordar a complexidade das causas produtoras de risco e sua relação com o desenvolvimento da modernidade e difunde a premissa de inevitabilidade, restando aos 'vulneráveis' a responsabilidade de se prevenirem e se adaptarem num processo de individualização do risco (S. Sulaiman, 2014). Esse contexto operacionaliza ainda o que chamamos de "inquestionabilidade do risco" (A. Aledo e S. Sulaiman, 2014, 2015), pois não se coloca em questão os processos de configuração e perpetuação da vulnerabilidade, nem a formação e proliferação das áreas de risco; o risco não está em questão, ele está posto, cabendo a cada indivíduo identificá-lo por meio das ferramentas da tecnociência e atuar em sua redução.

\section{Conhecer para se autoproteger: a educação como individualização do risco}

As precipitações intensas e concentradas são fenômenos naturais que estabelecem estreita relação com a ocorrência de desastres naturais. No entanto, inundações/ enchentes e deslizamentos não podem ser entendidos apenas como eventos naturais, sem considerar, nas cidades brasileiras, o papel do modelo de sociedade e de desenvolvimento na produção de riscos e vulnerabilidades de territórios e grupos humanos (J. Warner et al., 2002; B. Winer et al., 2004). Os elevados registros de desastres naturais, causados por eventos climáticos extremos, apontam uma relação sinérgica entre altos índices pluviométricos, que tendem a aumentar com o avanço dos impactos das mudanças climáticas (IPCC, 2007; 2014), e condições de vulnerabilidade nas cidades brasileiras (C. Nobre et al., 2010), historicamente constituídas no desenvolvimento urbano do país (R. Rolnik, 1999). Nas palavras de N. Valencio (2009b, p. 25), "o desastre mata, antes de tudo, o que se encontra pobre".

Evidencia-se também uma debilidade na gestão dos riscos de desastres no Brasil. Por um lado, a gestão reativa (F. Nogueira, 2002), baseada em ações de resposta e reconstrução do pósdesastre, estruturou a formação da Defesa Civil brasileira a partir da $2^{\mathrm{a}}$ Guerra Mundial (T. Gobatto, 1997; L. Castro, 1999), abrindo uma lacuna na gestão preventiva, que vem ganhando maior amplitude contemporaneamente. No entanto, mesmo as ações preventivas ainda estão instituídas dentro de uma gestão corretiva do risco (CEPED-UFSC, 2014), baseada em controle da natureza (I. Burton et al., 1978), capacidade técnica e institucional de enfrentamento (K. Hewitt, 1983) e mudança do comportamento humano, sem uma análise densa sobre a realidade social brasileira ( $\mathrm{N}$. Valencio, 2009).

Com base na análise do corpus, tanto a segunda categoria “medidas de prevenção" como a terceira categoria "planejamento em situações de emergência”, tiveram mensagens orientacionais direcionadas à mudança de comportamento e adoção de atitudes relativas à redução do risco de desastre e à resposta. Esse direcionamento resultou em uma construção gramatical, quase preponderante, bastante verificável nos materiais impressos. Por um lado, a conjugação do verbo no modo imperativo (Retire/Não Retire, por exemplo), ou no infinitivo com valor de imperativo (Retirar/Não retirar, por exemplo), tem o intuito de advertir, aconselhar o interlocutor a cumprir a ação indicada pelo verbo, funcionando, portanto, como exortação, conselho, convite (C. Cunha, 2001, p. 477-480). Por outro lado, o uso do "não" sistemático aponta um discurso de caráter proibitivo, sendo pouco mobilizador, já que indica um impedimento e não o seu revés, o procedimento: por exemplo, em vez de "não retirar a vegetação" antes “manter a vegetação" como já ilustrado na fig. 2 e também observado no excerto abaixo:

\section{“COMO REDUZIR OS RISCOS:}

- não retirar a vegetação, principalmente de lugares muito inclinados;

- não lançar água servida no barranco;

- não deixar acumular águas das chuvas no barranco;

- não deixar vazamentos da rede de água e de esgoto cair no barranco;

- não construir fossas em terrenos muito inclinados, pois podem proporcionar escorregamentos;

- não fazer cortes em barranco muito inclinado;

- não lançar o lixo nas encostas de morros;

- não aterrar encostas ou morros para construir principalmente com lixo, pois pode provocar escorregamento;

- não construir em cima de barrancos que possam deslizar, carregando sua casa;

- não construir embaixo de barrancos que possam deslizar, soterrando sua casa;

- não construir nas margens de rios e canais. Isto é perigoso e proibido;

- não plantar bananeiras e árvores grandes em morros, pois, acumulam água no solo e provocam escorregamentos; conserve a vegetação nas margens dos rios e canais para impedir a erosão - folheto Prevenção em áreas de risco - Diadema" (Diadema, 2013).

Além dos materiais impressos e audiovisuais, o curso de capacitação e as reuniões comunitárias também foram construídos como ferramentas para auxiliar o diagnóstico das áreas de risco e orientar a adoção de comportamentos que favoreçam a auto-proteção. Não são espaços de discussão sobre as causas socio-históricas do risco de desastre local, mas sim sobre como enfrentálo. Partindo da premissa de que "educação e saber fornecem à sociedade estratégias de auto-ajuda que diminuem sua vulnerabilidade e melhoram sua vida" 
(UNESCO, 2005: 55), materiais e práticas educativas para prevenção têm-se apoiado na responsabilização dos indivíduos que vivem em áreas de risco e de pessoas que atuam nesse campo. Dentro de uma gestão corretiva do risco (CEPED-UFSC, 2014), os conteúdos e práticas educativas pouco, ou quase nunca, abarcam os problemas sociais, políticos, econômicos, especialmente relacionados com problemas históricos de urbanização das cidades brasileiras (R. Rolnik, 1999; IBAMA, 2002; MMA, 2007; A. Young e D. Hogan, 2010).

Mais que responsabilização, há um processo de "culpabilização da vítima”, que significa "uma brilhante ideologia para justificar a forma perversa de ação social desenhada para mudar, não a sociedade, como se poderia esperar, mas sim as vítimas da sociedade", como define o sociólogo W. Ryan (1978, p.8), que analisou a situação de negros, pobres e trabalhadores nos Estados Unidos durante a década de 1970. Nesse contexto, há um processo de diferenciação que marca a dificuldade pessoal e a má adaptação da vítima à sociedade, o que seria, portanto, a causa, individual, dos problemas sociais. Essa diferenciação, no caso das vítimas de inundações/enchentes e deslizamentos, refere-se à caracterização das populações localizadas em áreas de risco, sem considerar que a pobreza estrutural e a urbanização acelerada sem uma correspondente gestão do território e políticas habitacionais levam grande parte da população a se instalar em áreas geográficas periféricas, sobreexpostas a ameaças por falta de condições naturais favoráveis e de infraestrutura urbana.

Para I. Veyret e N. Richemond (2007), esse processo revela três questões básicas: a) ocupação de áreas de baixo custo, distantes do centro, ambientalmente frágeis e sem infraestrutura urbana; b) degradação ambiental e construções de baixa qualidade por falta de conhecimento e recursos adequados; e c) falta de consciência do risco e fatalismo já que têm relevância as preocupações advindas de riscos específicos dos conflitos sociais relativos ao modo de vida urbano. Dessa forma, a "individualização do risco" parte da estigmatização da origem do problema social como individual, até mesmo genética, e paralisa o processo de justiça social.

Em diálogo com o "enfoque tecnocêntrico", a perspectiva da "individualização do risco" nos conteúdos e práticas de educação para prevenção indica o predomínio de uma abordagem de responsabilização dos indivíduos envolvidos com áreas de risco, por meio da aquisição de conhecimentos tecnocientíficos que permitem a percepção do risco e indicam como atuar para a convivência com o risco e a auto-proteção, diminuindo assim a vulnerabilidade de indivíduos, grupos e comunidades ante um desastre. Busca-se atuar sobre as situações concretas e verificáveis sem explicitar as causas profundas e os processos que as configuraram, deixando-se de possibilitar diálogos críticos e compartilhamentos de visões para a definição de estratégias locais que não sigam reproduzindo vulnerabilidades.

Segundo B. Wisner et al. (2004[1994]), a vulnerabilidade pode ser entendida em escalas, partindo da situação concreta até sua análise ideológica. As "causas profundas", relacionadas com a distribuição de poder e o modelo de organização social, estão longe do problema concreto e orientam "processos dinâmicos" que podem originar "condições inseguras", numa escala de progressão da vulnerabilidade. Essa perspectiva desenha a vulnerabilidade dentro de um processo socio-histórico de desdobramentos e interrelações e promove, especialmente no Brasil, a perpetuação de um modelo excludente/negligente de “urbanização de risco" (R. Rolnik, 1999). Dessa forma, por exemplo, barracos na beira de um córrego apresentam "condições inseguras" frente a um evento de inundação, mas a ocupação dessas áreas corresponde a "processos dinâmicos" de crescimento populacional e falta de políticas habitacionais, que respondem a interesses políticos e econômicos de investimentos em áreas urbanas de classe Ae $B$, que podem ser identificados se forem buscadas as "causas profundas" da vulnerabilidade atribuída àqueles barracos.

No entanto, a gestão de risco e seus desdobramentos na educação para a prevenção, dirigem-se a atuar sobre o controle ou manejo tecnocientífico das ameaças e a tentar minimizar as condições mais superficiais e locais (condições inseguras). Não se coloca que a própria sociedade é produtora de vulnerabilidade e de áreas de risco, não se coloca que é do contexto sociopolítico que partem as desigualdades do desenvolvimento que produz a vulnerabilidade. Assim, os fatores de produção de vulnerabilidade e, portanto de risco, relacionados com estruturas sociais desiguais, são omitidos para se continuar um desenvolvimento insustentável cujo modelo socioeconômico serve para concentrar os benefícios em poucas mãos e socializar as externalidades ambientais e sociais que provoca (A. Aledo e S. Sulaiman, 2015).

\section{Conclusões}

Diante das perguntas de investigação: 0 que é educar para a prevenção de desastres naturais?, este trabalho identificou que a abordagem educativa frente aos riscos e desastres naturais tem-se centrado na promoção de uma mudança do comportamento para que indivíduos, grupos e comunidades saibam conviver com o risco. Busca-se informar sobre como diagnosticar os elementos e territórios em risco e sobre como agir de forma preventiva, por meio da indicação de medidas adequadas de segurança ao público e especialmente a moradores em áreas de risco.

A educação para prevenção de desastres desenvolve-se a partir da premissa do "conhecer para prevenir" por meio de um processo comunicativo unidirecional 
(Lasswell, 1971), cujo emissor (instituições tecnológicas e acadêmicas e governamentais) produz e dissemina informações; o receptor (agentes de defesa civil, técnicos e agentes públicos, moradores em áreas de risco e sociedade civil) recebem as informações; o canal (materiais e atividades educativas) é o suporte para transmitir informação e capacitar; a mensagem (informações técnicas e comportamentos e atitudes de autoproteção) é padronizada; e o efeito (sobre o receptor) é a percepção de risco e mudança comportamental para conviver com o risco.

Tanto os materiais quanto às práticas educativas sob análise apresentaram dados importantes sobre como se pensa e se aplica a educação para prevenção de desastres no Brasil, tendo como recorte geográfico o $A B C$ Paulista, na região metropolitana de São Paulo. A abordagem pedagógica está baseada na relação transmissãoassimilação de conhecimentos, tanto sobre os desastres naturais relacionados a inundações/enchentes e deslizamentos, quanto sobre como agir frente a eles.

Dessa forma, quanto à segunda pergunta desta pesquisa: Quais são os limites e possibilidades da educação para a prevenção de desastres?, observou-se que a difusão de informações para a prevenção de desastres tem um papel relevante na sensibilização sobre os desastres naturais nas cidades brasileiras. Mas essa abordagem educativa deixa de abarcar a questão dos desastres naturais como problema social, político, econômico, especialmente relacionado com processos históricos de urbanização e exclusão social das cidades brasileiras, o que poderia ser contemplado na tipologia de perigos naturais, mistos, tecnológicos/antrópicos. Diferentemente de um processo mecanicista de "aquisição de saber para saber fazer", entendemos a educação como um processo de construção contextualizada de conhecimentos que envolve uma abordagem dialogada, crítica, problematizadora, de longo prazo, que investigue o tema/problema de aprendizagem.

O processo de transmissão e assimilação de conhecimento como um "ato de depositar" (Freire, 1987 [1970]), significa um instrumento de opressão e alienação. Baseiase numa relação hierárquica entre ensino-aprendizagem, em que o professor se constitui sujeito do processo educativo, e os alunos objetos desse processo direcionado à adaptação, integração, ajustamento desses "objetos" à engrenagem social, sem possibilidade de contestála. Há a indicação de comportamentos e atitudes de prevenção e auto-proteção para orientar medidas de adaptação e convivência, partindo-se da premissa de inevitabilidade do risco e da sua responsabilização individual (Sulaiman, 2014). Essa abordagem educativa presente nos processos comunicativos de prevenção de desastres naturais, portanto, operacionalizam o conceito de "inquestionabilidade do risco".
Explicitar a complexidade das questões ambientais, entre elas os desastres naturais, e possibilitar a construção coletiva, participativa e contextualizada de conhecimento são relevantes para a construção de uma cultura de prevenção de desastres no país e de comunidades/cidades resilientes no mundo. Para tanto, a relação entre educação e risco precisa tematizar as causas sociais que produzem o risco e criar oportunidades de superá-las por meio do diálogo entre atores sociais e seus saberes para que a resiliência seja mais que uma correção estrutural ou comportamental, mas sim a construção - contínua, crítica e participativa - de grupos, comunidades, bairros, cidades resilientes.

\section{Referências bibliográficas}

Aledo, A. T., Sulaiman, S. N. (2014). La incuestionabilidad del riesgo. Ambiente e Sociedade. São Paulo, v. XVII, n. 4, p. 9-16, out.-dez.

Aledo, A. T., Sulaiman, S. N. (2015). La incuestionabilidad del riesgo: vulnerabilidad social e riesgo sísmico en municipios turísticos. Cuadernos de Turismo, n. 36, pp. 17-37.

Alheiros, M. M. (2011). Gestão de riscos geológicos no Brasil. Revista Brasileira de Geologia de Engenharia e Ambiental, v. 1, n 1, nov., pp. 109-122. Disponível em: http://itpack31.itarget.com.br/uploads/abe/arquivos/ RevistaABGEMargarethpdf.pdf, Acesso em: 02/12/2012.

Bardin, L. (2009[1977]). Análise de conteúdo. Trad. Luís A. Reto e Augusto Pinheiro. Lisboa: Edições 70.

BM - BANCO MUNDIAL (2012a). Avaliação de Perdas e Danos: Inundações Bruscas em Pernambuco - Junho de 2010. Joaquin Toro (coord.). Brasília, agosto.

BM - BANCO MUNDIAL (2012b). Avaliação de Perdas e Danos: Inundações Bruscas em Santa Catarina - Novembro de 2008. Joaquin Toro (coord.). Brasília, novembro.

BM - BANCO MUNDIAL (2012c). Avaliação de Perdas e Danos: Inundações Bruscas em Alagoas - Junho de 2010. Joaquin Toro (coord.). Brasília, novembro.

BM - BANCO MUNDIAL (2012d). Avaliação de Perdas e Danos: Inundações e Deslizamentos na Região Serrana do Rio de Janeiro - Janeiro de 2011. Joaquin Toro (coord.). Brasília, novembro.

BRASIL. Lei n. 12.608, de 10 de abril de 2012. Institui a Política Nacional de Proteção e Defesa Civil - PNPDEC; dispõe sobre o Sistema Nacional de Proteção e Defesa Civil - SINPDEC e o Conselho Nacional de Proteção e Defesa Civil - CONPDEC; autoriza a criação de sistema de informações e monitoramento de desastres; altera as Leis no 12.340/2010, 10.257/2001, 6.766/1979, 8.239/1991, e 9.394/1996; e dá outras providências, 2012.

Burton, I., Kates, R. W., White, G. F. (1978). The Environment as Hazard. New York: Oxford University Press. 
Castro, A. L. C. de. (1999). Manual de Planejamento em Defesa Civil, v. I, II e III. Brasília-DF, Imprensa Nacional.

CEPED-UFSC - CENTRO UNIVERSITÁRIO DE ESTUDOS E PESQUISAS SOBRE DESASTRES / UNIVERSIDADE FEDERAL DE SANTA CATARINA (2014). Capacitação básica em Defesa Civil: livro texto para educação à distância. Janaína Furtado; Marcos de Oliveira; Maria Cristina Dantas; Pedro Paulo Souza; Regina Panceri (eds). 5. ed. Florianópolis: CEPED-UFSC, 157 p. Disponível em: http://labgestao. ufsc.br/portal/dc5/, Acesso em: 25/05/2014.

Cerri, L. E. S., Nogueira, F. R. (2012). Mapeamento e gestão de riscos de escorregamentos em áreas de assentamentos precários. In: Guimarães, S.T.L.; CARPI Jr., S.; Godoy, M.B.R.B. (orgs) Gestão de áreas de riscos e desastres ambientais. Rio Claro, IGCE/ UNESP, pp. 285-304.

CONSÓRCIO INTERMUNICIPAL DO GRANDE ABC PAULISTA (s/d.). Juntos, vamos proteger o Grande $A B C$ das chuvas. Folheto. Disponível em: https://goo.gl/JwaiY2. Acesso em: 28/04/2017.

Cunha, C. (2001). Nova gramática do português contemporâneo. 3 ed. Rio de Janeiro: Nova Fronteira.

Gil, A. C. (1994). Métodos e técnicas de pesquisa social, São Paulo, Atlas.

Gobatto, T. A. (1997). Defesa civil. Apostila. Dpto. Defesa Civil, Secr. Esp. de Políticas Regionais, SEMPRE/ MPO, Dp. Defesa Civil, Brasília.

Hewitt, K. (ed.) (1983). Interpretations of Calamity. Boston: Mass Allen \& Unwin.

Freire, P. (1987[1970]). Pedagogia do oprimido. 17 ed. Rio de Janeiro: Paz e Terra.

IBAMA - INSTITUTO BRASILEIRO DO MEIO AMBIENTE E DOS RECURSOS NATURAIS RENOVÁVEIS (2002). GEOBRASIL Perspectivas do meio ambiente no Brasil. BrasíliaDF: Edições IBAMA, Disponível em: http://www. ceped.ufsc.br/sites/default/files/projetos/geo_ brasil_p.pdf, Acesso em: 19.09.2012.

IPCC - PAINEL INTERGOVERNAMENTAL DE MUDANÇAS CLIMÁTICAS (2014). Climate Change 2014: Impacts, Adaptation, and Vulnerability. Working Group II Contribution to the IPCC $5^{\text {th }}$ Assessment Report - Changes to the Underlying Scientific/ Technical Assessment. Disponível em: http://www.ipcc. ch/report/ar5/wg2/, Acesso em: 09/05/2014.

IPCC - PAINEL INTERGOVERNAMENTAL DE MUDANÇAS CLIMÁTICAS (2007). Mudança Climática 2007: A base da ciência física. Resumo para os elaboradores da política. Contribuição do Grupo de Trabalho I para o Quarto Relatório de Avaliação do Painel Intergovernamental. Disponível em: http://goo.gl/qcMztn, Acesso em: 12.08.2011.

IPT - INSTITUTO DE PESQUISA TECNOLÓGICAS (2012a). Áreas de risco: informação para prevenção. Vídeo, IPT,
Prefeitura de Mauá. Disponível em: http://www.ipt. br/noticia/551-riscos_ambientais_em_imagens.htm, Acesso em: 28/04/2014.

IPT - INSTITUTO DE PESQUISA TECNOLÓGICAS (2012b). Riscos ambientais em imagens: Vídeo do IPT que orienta para prevenção de riscos é apresentado em audiência pública no município de Mauá. Notícias, 25.07.12. Disponível em: http://www.ipt.br/noticia/551-riscos_ ambientais_em_imagens.htm, Acesso em: 28/04/2017.

IPT - INSTITUTO DE PESQUISA TECNOLÓGICAS (2014). Gestão de riscos no $A B C$ : Consórcio de municípios da região paulista assina contrato com IPT para elaboração de planos de redução de riscos. Notícias. Disponível em: http: / /www. ipt.br/noticia/607.htm, Acesso em: 28/04/2017).

Lasswell, H. D. (1971[1927]). Propaganda technique in the world war. Nova lorque: MIT Press.

MC - MINISTÉRIO DAS CIDADES; IPT - INSTITUTO DE PESQUISAS TECNOLÓGICAS; CEPED-UFSC. (s/d.). Capacitação em Mapeamento e Gerenciamento de Risco. Agostinho Tadashi Ogura, Eduardo Soares de Macedo, et al. (org). Brasília. Disponível em: http://goo.gl/Ugmt69, Acesso em: 20/04/2014.

Minayo, M. C. S. (org.) (2010). Pesquisa social: teoria, método e criatividade. 29 ed. Petrópolis, RJ: Vozes (Coleção temas sociais).

MMA - MINISTÉRIO DO MEIO AMBIENTE (2007). Enchente $e$ inundação. Vulnerabilidade Ambiental - Desastres Naturais ou fenômenos induzidos? Brasília-DF, 192 p.

Nobre, C. A., Young, A. F., Saldiva, P., Marengo, J. A., Nobre, A. D., Alves Jr., S., Moreira da Silva, G. C., Lombardo, M. (2010). Vulnerabilidades das megacidades brasileiras às Mudanças Climáticas: Região Metropolitana de São Paulo. Sumário Executivo. Rio Claro: INPE/UNICAMP/USP/IPT/UNESP.

Nogueira, F. R. (2002). Gerenciamento de riscos ambientais associados a escorregamentos: contribuição às políticas públicas municipais para áreas de ocupação subnormal (Tese de Doutorado). Universidade Estadual Paulista, Instituto de Geociências e Ciências Exatas, Rio Claro.

PREFEITURA DIADEMA (2013). Prevenção em áreas de risco - Diadema. Folheto. Ministério das Cidades, Caixa Econômica Federal, REGEA-Geologia e Estudos Ambientais, janeiro.

PREFEITURA MAUÁ, DEFESA CIVIL DE MAUÁ (s/d). Defesa Civil na Escola. Cartilha.

PREFEITURA MAUÁ, IPT (2012). Prevenção em áreas de risco Mauá. Folheto, julho.

PREFEITURA SANTO ANDRÉ (s/d). Juntos, vamos proteger Santo André das Chuvas. Folheto. SEMASA - Serviço Municipal de Saneamento Ambiental de Santo André. 
Petal, M. (2008). Disaster prevention for schools: guidance for education sector decision-makers. Suiça, UNISDR - Thematic Platform for Knowledge and Education, 2008.

Rolnik, R. (1999). Para além da lei: legislação urbanística e cidadania (São Paulo 1886-1936). In: Souza, M. A. A.; Lins, S. C.; Santos, M. do P. C.; Santos, M. da C. (org.) Metrópole e Globalização - Conhecendo a cidade de São Paulo. São Paulo: Editora CEDESP.

Ryan, W. (1976). Blaming the victim. Ed. Rev. Nova lorque: Vintage Books Edition.

SÃo CAETANO DO SUL (s/d.). Boca de Lobo não come lixo. Campanha de conscientização contra enchentes, Folheto, DEA - Departamento de Água e Esgoto.

SBC - SÃO BERNARDO DO CAMPO, PREFEITURA DO MUNICÍPIO (2013). Operação Guarda-Chuva 2014. Folheto.

SBC - SÃO BERNARDO DO CAMPO, PREFEITURA DO MUNICÍPIO (2012a). Operação Guarda-Chuva 2013. Folheto.

SBC - SÃO BERNARDO DO CAMPO, PREFEITURA DO MUNICÍPIO (2012b). Operação “Guarda-Chuva” 2012/2013. Cartaz/Calendário

SBC - SÃO BERNARDO DO CAMPO, PREFEITURA DO MUNICÍPIO (s/d.). Defesa civil para crianças: caderno para colorir. Caderno. Governo do Estado de São Paulo, CEDEC, SBC.

Silva, F. C., Macedo, E. S. (2007). Percepção ambiental e riscos naturais com enfoque em deslizamentos, in: Simpósio Brasileiro de Desastres Naturais e Tecnológicos - SIBRADEN, II. Santos, Anais..., dez.

Sulaiman, S. N. (2014). De que adianta? O papel da educação para a prevenção de desastres (Tese Doutorado - Faculdade de Educação), São Paulo, Universidade de São Paulo.

UFABC - UNIVERSIDADE FEDERAL DO ABC (2015). Apoio a Construção de Política Pública Regional de Gestão de Risco de Desastres no Grande $A B C$. Oficinas de Capacitação e Debate. Pró-Reitoria de Extensão da UFABC, Consórcio Intermunicipal do Grande ABC. Disponível em: http://gestaoderiscosabc. wixsite.com/apoio. Acesso em: 27/04/2017.

UNDRO - UNITED NATIONS DISASTER RELIEF OFFICE (1991). Mitigating natural disasters: phenomena, effects and options. A manual for policy and planner. Nova lorque, Nações Unidas.

UNESCO - ORGANIZAÇÃO DAS NAÇÕES UNIDAS PARA A EDUCAÇÃO, A CIÊNCIA EA CULTURA; UNICEF - FUNDO DAS NAÇÕES UNIDAS PARAA CRIANÇA (2012). Redução do risco de desastres nos currículos escolares: Estudos de Casos de Trinta Países. David Selby e Fumiyo Kagawa. Espanha, julho. Disponível em: http://unesdoc.unesco.org/images/0022/002205/220517por.pdf. Acesso em: 27/04/2017.
UNESCO (2005[2004]). Década das Nações Unidas da educação para o desenvolvimento sustentável (20052014). Documento final - Plano Internacional de Implementação [United Nations Decade of Education for Sustainable Development 2004-2005 - Draft International Implementation Scheme]. Brasília, Unesco no Brasil. Disponível em: http://unesdoc. unesco.org/images/0013/001399/139937por.pdf, Acesso em: 27/11/2016.

UNISDR - ESTRATÉGIA INTERNACIONAL PARA REDUÇÃO DE RISCO DE DESASTRE DAS NAÇÕES UNIDAS (2005). Marco de Ação de Hyogo 2005-2015. Aumento da resiliência das nações e das comunidades frente aos desastres. Trad. de "Hyogo Framework for Action (2005-2015)”. Disponível em: http: / /www.unisdr.org/eng/hfa/hfa.htm\&gt. Acesso em: 17/12/2011.

UNISDR (s/d.). Construindo Cidades Resilientes: Minha Cidade está se preparando! - Campanha Mundial de redução de desastres. Versão brasileira. MIN, UFSC, CEPED.

Valencio, N. F. L. S. (2009b). O Sistema Nacional de Defesa Civil (Sindec) diante das mudanças climáticas: desafios e limitações da estrutura e dinâmica institucional. In: Valencio, N. F. L. S.; M. Siena; V. Marchezini; J. C. Gonçalves (org.) Sociologia dos desastres. São Carlos: Rima Editora, pp. 19-33.

Valencio, N. F. L. S. (2009a). Da norte da Quimera à procura de Pégaso: a importância da interpretação sociológica na análise do fenômeno denominado desastre. In: Valencio, N. F. L. S., M. Siena, V. Marchezini, J. C. Gonçalves (org.) Sociologia dos desastres. São Carlos: Rima Editora, pp. 03-18.

Veyret, Y., Richemond, N. M. (2007). O risco, os riscos. In: Veyret, Y. (org) Os riscos: o homem como agressor e vítima do meio ambiente. Trad. Dilson Ferreira da Cruz. São Paulo: Contexto, pp. 23-80.

Young, A. F., Hogan, D. J. (2010). Dimensões humanas das mudanças climáticas: vulnerabilidade as enchentes e inundações na Região Metropolitana de São Paulo. In: XVII Encontro Nacional de Estudos Populacionais. Caxambú, ABEP, Anais..., set. Disponível em: http:// www.abep.nepo.unicamp.br/encontro2010/docs_pdf/ eixo_3/ abep2010_2358.pdf. Acesso em: 10/04/2014.

Warner, J., Waalewijn, P., Hilhorst, D. (2002). Public Participation in Disaster-Prone Watersheds: Time for Multi-Stakeholder Platforms?, Disaster site 6, Wageningen university. Irrigation and water management group. Disaster studies.

Wisner, B., Blaikie, P., Cannon, T., David, I. (2004 [1994]). At risk: natural hazards, people's vulnerability and disasters. 2 ed., London, New York, Routledge. 